\title{
In situ detection of inaccurate gas flow meters using a fingerprint technique
}

\author{
Ulf RC Nilsson *, Jerker Delsing \\ Luleå University of Technology, 97187 Luleå, Sweden
}

Received 25 November 1997; accepted 26 June 1998

\begin{abstract}
This work describes an in situ method for the testing of mechanical flow meters. The method was developed on diaphragm gas meters, but can be applied to most mechanically-based flow meters. The proposed fingerprint method analyses the behaviour of the meter during a work cycle. The result from the analysis is a "fingerprint" of the meter, in which mechanical errors in the meter can be detected. This is explained by the mechanical connection between the sensing mechanism and the mechanical output from the meter. An error analysis of a diaphragm meter was carried out to deduce the type of errors that are likely to occur in such meters. The most severe malfunctions are leakage, internal friction and liquid in the meter. These errors can either lead to measuring errors or can cause the meter to cease functioning. The fingerprint method has been tested on meters with simulated errors and on used meters taken from the gas grid in Lund. The fingerprint method can correctly diagnose errors such as leakage, increased friction and liquid in the meter. () 1998 Elsevier Science Ltd. All rights reserved.
\end{abstract}

Keywords: In situ testing; Meter proving; Fingerprint; Diaphragm meter

\section{Introduction}

The need to ensure that an installed flow meter continues to be accurate is as old as the flow metering problem itself. Thus, numerous methods to address this problem have been devised. Such methods include in situ measuring techniques such as clamp-on meters, dilution and tracer methods, as well as exchange schemes with subsequent lab calibration.

In the gas industry, meter errors involve a substantial amount of money. This has, for example, been shown in the Gas Research Institute (GRI) report on UnAccounted For gas flow (UAF) [1]. The largest contributors to UAF in the GRI investigation were measurement errors (81.64\% of UAF), with the remainder split between leakage $(8.85 \%)$, theft $(6.54 \%)$ and accounting $(2.97 \%)$.

A typical gas grid consists of a large number of small meters (used in smaller houses and apartments) and a

* Corresponding author. Address to: Flowmeter Diagnostics, Flygelvagen 237, 22472 Lund, Sweden. E-mail: ulf.nilsson@lund.mail.telia.com small number of large meters (used in industries). For example, in the Swedish gas grid, there are approx. 50,000 meters, of which about 43,000 meters are small, domestic gas meters. The large meters are checked frequently and are carefully monitored due to the large quantities measured. The primary on-site methods used to detect the faulty operation of gas flow meters are tracer and master meter techniques [2-4]. Portable provers can also be used, but this requires extra piping. These methods, which are used on large meters, are not applicable to smaller meters, both because of practical considerations and economic factors. Therefore, smaller meters will not be checked as often as large meters, due to the comparatively high cost of calibration in relation to the value of the meter, and the measured quantity. This problem is approached in different ways. Some operators test meters after 10 years or more, while others take random samples, test them and act according to the results. Meters are also checked on demand of the customer.

The general problem is to find inaccurate meters as soon as possible after they became inaccurate, using an inexpensive and simple method.

For this purpose, a two-step approach is suggested. 
First, a cheap high level screening, is introduced. Such a method can be the LoadIndex method, which is based on billing readings suggested by the author [5]. The method is based on the assumptions that most meters are correct, and the load is primarily dependent on the climate. By identifying outlying installations, installations with suspect meter errors can be detected. The method has been tested in Sweden and has shown promising results. Another method, using a similar approach to supervise district heating meters, has been suggested by Bernt Svensson [6].

Using a screening method, meters identified as suspect from a metering error point of view can either be exchanged directly or be examined using an in situ test method. For this purpose, we here propose such an in situ test method.

The basic idea is to analyse the generic flow signal of the flow meter. An ideal functioning meter will give a flow signal that includes only the frequency components that are present in the fluid flow. Frequencies that are carried by the fluid flow are caused by turbulence and flow pulsation. Pulsating flow will be able to influence flow meter operation. This area is well documented in the literature [7-13]. A method to detect the influence of pulsating flow on a turbine flow meter was proposed by Viljeer [14]. However, little or nothing has been found related to positive displacement meters and diaphragm meters. The turbulent energy is often too small to propagate into the generic output of mechanically based flow meters, such as diaphragm meters.

In a non-ideal mechanical flow meter, the mechanical design will introduce additional frequencies into the generic flow signal of the meter. Thus, the basic assumption made in this paper is that a meter that is not working properly will exhibit a different dynamic behaviour, compared to an ideally working meter. Thus, it is here proposed that by analysing the generic flow signal, it will be possible to draw conclusions as to whether or not the meter operates correctly.

The proposed test method has been applied to diaphragm gas meters that are common in smaller gas billing installations. By measuring the outgoing shaft rotation at constant gas flow, a "fingerprint" of the meter is taken. This fingerprint should then reflect inadequate behaviour in the meter work cycle. These behaviours can then result in erroneous measurement. Analyses of the fingerprint have been made on a number of diaphragm meters. Both correctly operating meters and meters with various defects that cause meter errors have been tested. These defects are, leakage, increased friction and liquid in the meter compartment. Results obtained show that the fingerprint is affected in different ways by all of these defects.

\section{Theory}

The proposed fingerprint method approach measures the rotation of the outgoing shaft of the meter to gather information about the flow and the meter. For diaphragm meters, the influence from the flow can be assumed to be small. Thus, detailed information on the rotation of the outgoing shaft mainly reflects the mechanical operation of the meter. Using an error analysis, the most significant source of metering error in an diaphragm meter is found. This analysis makes a connection between mechanical operation and the metering error. Because of this, it is likely that erroneous meter operation will be reflected in the rotation of the outgoing shaft of the meter.

The diaphragm meter is a volumetric gas meter that measures the gas mechanically. In Fig. 1, a typical meter is shown in a cutaway picture, with the principle parts indicated. In Fig. 2, the operation is shown with an accompanying explanatory note. The function is only described for one measuring compartment, but both operate in the same manner (with only a phase difference).

The errors that can occur in a diaphragm meter can be divided into two groups: 1) errors that depend on altered physical properties, and 2) errors due to incorrect operation. In the first group, it is primarily pressure changes that affect the measurements. The second group includes errors such as leakage, geometrical changes and mechanical failure. To investigate how the different errors affect the total measurement uncertainty, an error analysis was carried out.

The basic function of a diaphragm meter is to count the number of times a volume is emptied and filled. Therefore, the ideal gas law is a natural starting point:

$V_{\mathrm{gas}}=\frac{n R T_{\mathrm{gas}}}{p}$

where $V_{\text {gas }}$ is the gas volume, $n$, the number of moles, $R$, the specific gas constant, $T_{\text {gas }}$, the absolute gas tem-

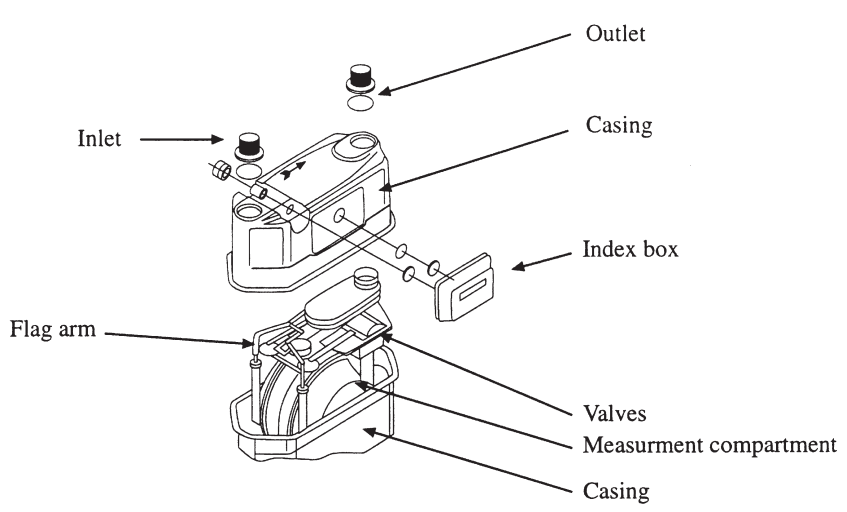

Fig. 1. Cutaway picture of a diaphragm meter. 

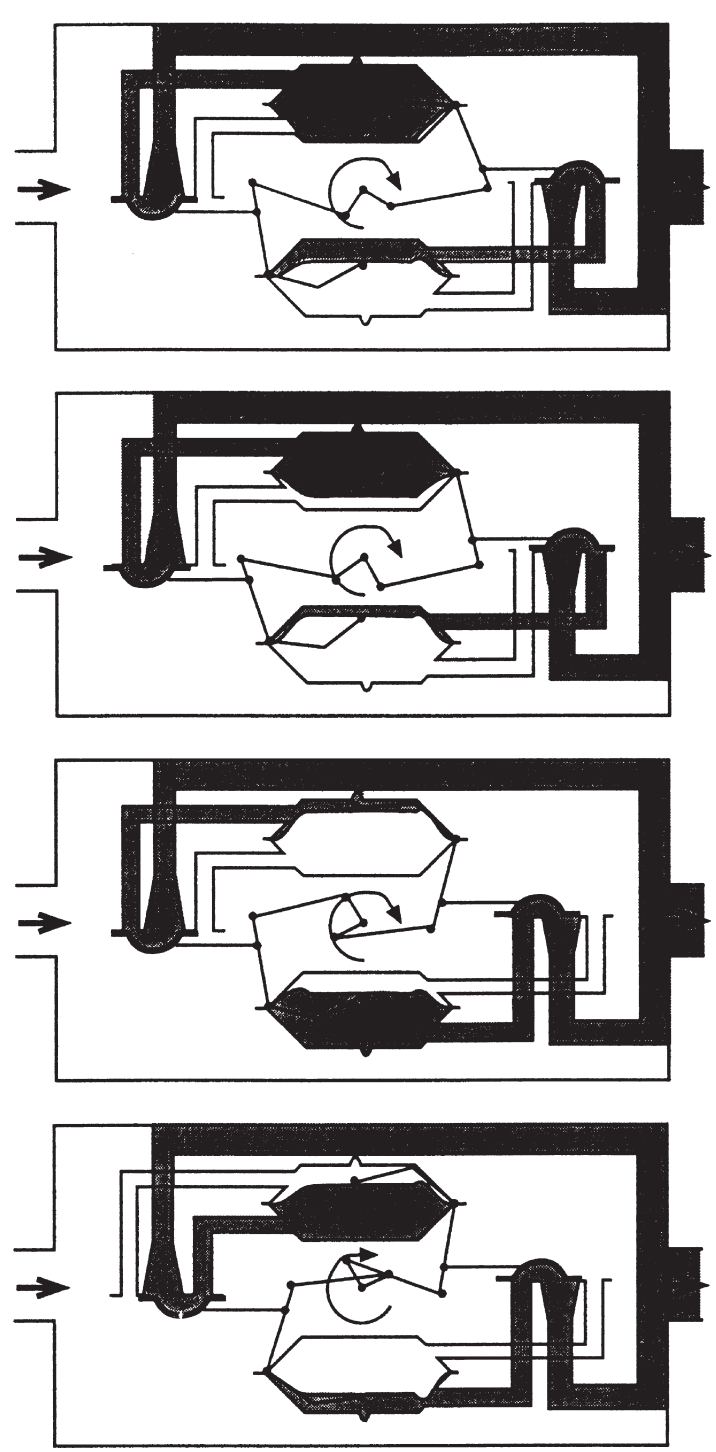

1st Phase:

The incoming gas (from the left) begins to fill the lower half, the diaphragm starts to move upwards and the gas in the upper half flows out of the meter (to the right).

2nd Phase:

The lower half continues to fill. The valve changes position, guided by the movement of the diaphragm.

3rd Phase:

The diaphragm is close to the wall, the lower half is almost filled and the valve is about to change position.

4th Phase:

The valve has changed position. The lower half is now emptied, and the upper half is filling. One volume of gas has been measured.

Fig. 2. Operation of a diaphragm meter.

perature and $p$, the absolute gas pressure. The gas pressure is determined by two factors: the atmospheric pressure and the gas pressure regulator. Therefore, the pressure is divided into two terms:

$p=p_{\text {gas }}+p_{\text {atm }}$

where $p_{\text {gas }}$ is the gas pressure, and $p_{\text {atm }}$, the atmospheric pressure. Modifying the gas law to real gases adds the compressibility factor, $z$. However in the pressure region in which these meters are used, the influence of $z$ can often be neglected.

$V_{\mathrm{gas}}=\frac{n R T_{\mathrm{gas}} z}{p_{\mathrm{gas}}+p_{\mathrm{atm}}}$

When literature in the field is studied, mainly the AGA gas measurement manual [15], a number of causes for incorrect metering are found. These lead to the introduction of factors that reflect these changes of operation in the meter. The volume that the meter measures is described by Eq. (4), with a set of transfer functions that reflect the geometrical changes $(G)$. The transfer functions can all be described as factors that change the transfer rate between the theoretical and actual geometry. $G_{\text {stretch }}$ can increase the volume if the diaphragm is stretched, $G_{\text {liquid }}$ reduces the volume, and $G_{\text {stroke }}$ can either increase or decrease the volume, depending on the change of the stroke.

$V_{\text {meter }}=\frac{n R T_{\text {gas }} z G_{\text {stretch }} G_{\text {liquid }} G_{\text {stroke }}}{p_{\text {gas }}+p_{\text {atm }}}$

The volume that is registered is the volume of the meter multiplied by the ratio $(r)$ of the gears in the index box. If there is a leakage in the meter, this will reduce 
the registered volume by a factor, $L$, and this factor can be divided into different terms depending on the locations from which they arise. $L_{\text {gasket }}$ is leakage that depends on missing or misplaced gasket. $L_{\text {diaphragm }}$ arises from holes in the diaphragm. $L_{\text {duct }}$ is the leakage from cracks or an otherwise damaged duct inside the meter.

$V_{\text {reg }}$

$=\frac{n R T_{\text {gas }} z G_{\text {stretch }} G_{\text {liquid }} G_{\text {stroke }}}{p_{\text {gas }}+p_{\text {atm }}} r L_{\text {gasket }} L_{\text {diaphragm }} L_{\text {duct }}$

Using Eq. (5), a standard error analysis [16] can be performed in order to see which errors are significant and which are less important.

$$
\begin{aligned}
& \frac{U_{\text {reg }}^{2}}{V_{\text {reg }}^{2}}=\frac{U_{\mathrm{n}}^{2}}{n^{2}}+\frac{U_{\mathrm{R}}^{2}}{R^{2}}+\frac{U_{2}^{2}}{\mathrm{z}^{2}}+\frac{U_{\mathrm{T}_{\text {gas }}}^{2}}{T_{\text {gas }}^{2}}+\frac{U_{\mathrm{p}_{\text {gas }}}^{2}}{\left(p_{\text {gas }}+p_{\text {atm }}\right)^{2}} \\
& +\frac{U_{\text {Patm }}^{2}}{\left(p_{\text {gas }}+p_{\text {atm }}\right)^{2}}+\frac{U_{\text {gear }}^{2}}{r^{2}}+\frac{U_{\text {stretch }}^{2}}{G_{\text {stretch }}^{2}}+\frac{U_{\text {Liquid }}^{2}}{G_{\text {liquid }}^{2}} \\
& +\frac{U_{\text {stroke }}^{2}}{G_{\text {stroke }}^{2}}+\frac{U_{\text {gasket }}^{2}}{L_{\text {gasket }}^{2}}+\frac{U_{\text {diaphragm }}^{2}}{L_{\text {diaphragm }}^{2}}+\frac{U_{\text {duct }}^{2}}{L_{\text {duct }}^{2}}
\end{aligned}
$$

The $U_{\mathrm{x}}$ in Eq. (6) marks the uncertainty for respective terms.

Since the purpose of this analysis is to investigate which errors affect the volume measurement, the number of moles, $n$, is held constant and $U_{\mathrm{n}}=0$. The physical properties of the gas: $R, z, T_{\text {gas }}, p_{\text {gas }}$ and $p_{\text {atm }}$, are affected by the composition of the gas and the installation conditions. The first two terms can be calculated from the composition of the gas and are also found in the literature [17]: $U_{\mathrm{R}}=0.00035 \mathrm{~J} / \mathrm{mol} \mathrm{K}, U_{\mathrm{z}}=0$. The remaining terms are dependent on the installation of the meter.

In most installations, the gas temperature in the meter is close to the air temperature at the meter. In the grid investigated, the gas temperature follows the air temperature with an offset of $3 \mathrm{~K}$, warmer in winter and cooler in summer [18]. However, the gas temperature is often assumed to be a fixed value, often $15^{\circ} \mathrm{C}$. If the average temperature over a year (1995 [19]) is taken as the uncertainty, we get $U_{\mathrm{T}}=6.4^{\circ} \mathrm{C}$. Another study aimed at determining gas temperature-dependent metering error was presented in a paper by Mobers [20]. He reported that the average error was between $4 \%$ and $10 \%$, depending on meter type.

The gas pressure is determined by the pressure regulator, which is in turn governed by the atmospheric pressure. The pressure regulator is set at $2.0 \mathrm{kPa}$ (20 mbar), with an accuracy of $\pm 2.5 \%$ [18], which gives $U_{\text {pgas }}=50 \mathrm{~Pa}$. In most cases, the atmospheric pressure is assumed to be $101.325 \mathrm{kPa}$, and the variation in pressure is measured to be between 100 and $102.0 \mathrm{kPa}$ (monthly average) [19], which gives $U_{\text {patm }}=1 \mathrm{kPa}$.
The leakage factors introduced in Eq. (5) can be both external (to the atmosphere) and internal leakage. The internal leakage is most difficult to detect and is the factor primarily addressed in this paper. Leakage to the atmosphere can occur in the gasket or in a damaged casing, but should be detected quickly, since an odorant is normally added to the gas. Meters with coaxial mounting (one pipe connection) can also have internal leakage in the gasket as well as external leakage. Since timeresolved flow measurements of the flow through the meter and the leakage have not been done, an exact analysis is not possible. However, a logical conclusion can be reached based on phenomena in the pressure cycle.

The general pressure drop over a normal functioning meter can be described as:

$\Delta p_{\text {fmeter }}=p_{\text {mean }}+\Delta p_{\text {amp }} \sin (\omega t)$

Since the flow will take the path of the smallest total pressure drop, three cases can be distinguished

- The pressure drop over obstacles $>$ the max. pressure drop of the meter: No leakage

- The pressure drop over obstacles $<$ min. pressure drop of the meter: No metering

- The pressure drop over obstacles between these borders: Leakage

The first case is not a problem, and the second can be detected without instruments, since the meter is not registering any flow. It is the third case that is the most interesting and the hardest to detect. If it can be assumed that the $\Delta p_{\text {leak }}$ is constant, a disturbance in the meter will occur when the $\Delta p_{\text {fmeter }}$ is at a minimum. All leakage can be regarded as equal, and the error can increase to $20-30 \%$ of the flow before it is detected. Thus, the uncertainty in leakage can be $U_{\text {gasket }}=U_{\text {duct }}=U_{\text {diaphragm }}$ $=30 \%$ of $L_{\mathrm{x}}$.

To eliminate the systematic error that occurs as a consequence of the variation of volume between meters during manufacturing of the meter, the meters are tested and adjusted via the cogwheels in the index box. They are switched so that the meter measures within specifications. The variation in ratio can be regarded as zero, $U_{\mathrm{r}}=0$.

An error that is mentioned in the AGA manual [15] is the pressure drop over the meter. In some systems, (as in Sweden), a pressure regulator is connected before the meter, and the gas pressure in the meter is constant. Any pressure drop will therefore lead to a lowered pressure after the meter. The metered volume will be constant, but the connected appliance, which is dependent on the outlet pressure from the meter, will be affected. An increasing pressure drop will eventually stop the operation of the appliance. If the pressure regulator is connected after the meter, an altered pressure drop will 
change the gas pressure in the meter and therefore lead to a meter error.

Since the diaphragm meter is a mechanical device that uses the gas pressure as the driving force, a set of equations describing the relationship between the pressure drop and the torque driving the mechanical index can be derived.

The force working in the diaphragm is dependent on the gas pressure $\left(p_{\text {gas } 1,2}\right)$ on both sides, and the area of the diaphragm $\left(A_{\text {diaphragm }}\right)$.

$F_{\text {diaphragm }}=\left(p_{\text {gas } 1}-p_{\text {gas } 2}\right) A_{\text {diaphragm }}$

The pressure difference $\left(p_{\text {gas } 1}-p_{\text {gas } 2}\right)$ can also be described as the pressure loss or pressure drop $\left(\Delta \mathrm{p}_{\text {gas }}\right)$ over the meter. The force is transferred through a set of flag arms $\left(\right.$ flag $\left._{1}\right)$ and bearings, to give the torque $\left(M_{\text {gas }}\right)$ necessary to operate the meter.

$M_{\text {gas }}=\Delta p_{\text {gas }} A_{\text {diaphragm }}$ flag $_{1}$

As can be seen in Eq. (9), a direct connection between the torque and gas pressure can be found. To determine what affects the torque, a more detailed analysis can be done.

$M_{\text {gas }}=M_{\text {index }}+M_{\text {transfer }}+M_{\text {bearing }}$

where $M_{\text {index }}$ is the torque used to turn the index, $M_{\text {transfer }}$ is the torque used to transfer the torque from the diaphragm to the bearing, and $M_{\text {bearing }}$ is the torque necessary to turn the outgoing shaft. $M_{\text {index }}$ is constant and necessary to operate the meter. In comparison, it is the final torque that is of most importance and which can change most significantly, and $M_{\text {bearing, }}$, thus increases the gas pressure drop. $M_{\text {bearing }}$ arises from the packing in the stuffing box and has two contradicting purposes: 1) to stop the gas from leaking, and 2) to allow the shaft to rotate. This is the only part that penetrates the casing, except for the inlet and the outlet.

The braking torque acting on a shaft in a bearing at the stuffing box can be calculated by

$M_{\text {bearing }}=A p_{\text {surface }} \mu d / 2$

where $A$ is the area of the shaft, $p_{\text {surface }}$ is the surface pressure, $\mu$, the friction coefficient and $d$, the diameter of the shaft. The area can be expressed as

$A=\pi d l$

with $l$ as the length of the shaft inside the stuffing box. Inserting into Eq. (11) gives

$M_{\text {bearing }}=\pi p_{\text {surface }} \mu d^{2} l / 2$
The terms in Eq. (13) that can change over time are $\mu$ and $p_{\text {surface. }}$ The friction and surface pressure can change due to ageing of the packing materials in the stuffing box. The other properties can be assumed to be constant. If the torque is translated into gas pressure (Eq. (9)), we get the following relationship between pressure drop created by the bearing and the changing terms:

$$
\begin{aligned}
& \Delta p_{\text {gas }} A_{\text {diaphragm }} \text { flag }_{1}=\pi p_{\text {surface }} \mu d^{2} l / 2+M_{\text {index }} \\
& +M_{\text {transfer }}
\end{aligned}
$$

Rearranging the terms results in the following:

$$
\begin{aligned}
& \Delta p_{\text {gas }}=\mu p_{\text {surface }}\left(d^{2} l / 2 A_{\text {diaphragm } \text { flag }}\right)+\left(M_{\text {index }}\right. \\
& \left.+M_{\text {transfer }}\right) / A_{\text {diaphragm }} \text { flag }_{1}
\end{aligned}
$$

The terms inside the parentheses will be constant, except for damage. As can be seen, however, any change in the friction or surface pressure will directly affect the pressure drop in the meter. As previously mentioned, the last two terms are small in comparison and can be neglected. We know from the experience of field workers that the friction in the stuffing box can increase until the meter stops. Therefore, this will be tested in the experiment.

The errors that depend on the mechanical operation of the meter are the transfer function and the leakage factors. The transfer functions, $U_{\text {stretch }}, U_{\text {liquid }}$ and $U_{\text {stroke }}$, introduced in Eq. (4), all have a directly proportional effect on the measured volume. $U_{\text {stretch }}$ allows a larger volume to be present in the measuring compartment when the dividing diaphragm or membrane is stretched. However, the volume is mainly limited by the rigid walls of the measuring compartment, so $U_{\text {stretch }}$ is likely to be limited. The risk is that the diaphragm can be folded and will then develop a hole that will leak. $U_{\text {liquid }}$ accounts for liquid that is present in the measuring compartment. The liquid can be condensate or can originate from water seeping in from a leaking grid. Regardless of the source or the composition of the liquid, the effect on meter performance is the same: the volume metered is reduced in proportion to the volume of the liquid. In new grids, the risk of liquid in the meter is small, but it can increase with age. $U_{\text {stroke }}$ is the effect of a change in the stroke that the diaphragm can accomplish, a shorter stroke reduces the volume, and a longer stroke increases the volume. The effect on the measuring capacity also depends directly on the change of the stroke. External force on the casing can result in an altered stroke, so that the measuring compartment is altered or flag arms are bent. However, these changes will normally result in errors so acute that the meter will stop functioning. $U_{\text {stroke }}$ is therefore assumed to be small.

When all of the previously mentioned uncertainties 
are summarised, we obtain the following results (Table $1)$.

By inserting data from Table 1 into Eq. (6), we obtain:

$$
\begin{aligned}
& \frac{U_{\text {reg }}^{2}}{V_{\text {reg }}^{2}}=0+1.77 \cdot 10^{-9}+0+4.9 \cdot 10^{-4} \\
& +2.3 \cdot 10^{-7}+9.37 \cdot 10^{-5}+0+\frac{U_{\text {stretch }}^{2}}{1}+\frac{U_{\text {Liquid }}^{2}}{1} \\
& +\frac{U_{\text {stroke }}^{2}}{1}+\frac{U_{\text {gasket }}^{2}}{1}+\frac{U_{\text {diaphragm }}^{2}}{1}+\frac{U_{\text {duct }}^{2}}{1}
\end{aligned}
$$

If $U_{\text {stretch }}, U_{\text {liquid, }}, U_{\text {stroke }}, U_{\text {gasket }}, U_{\text {diaphragm }}$ and $U_{\text {duct }}$ are assumed small, we get a metering error of $2.4 \%$. The effect on the total uncertainty of $U_{\text {stretch }}, U_{\text {liquid }}, U_{\text {stroke }}$, $U_{\text {gasket, }}, U_{\text {diaphragm }}$ and $U_{\text {duct }}$ is strong. If one of these unknown terms is increased to $5 \%$, the total uncertainty will increase to $5.6 \%$. It is also these terms that can only be found by testing the function of the meter. The other terms, including temperature, pressure and gas composition, can all be measured with an accuracy of $1 \%$ or better. In some cases, the temperature and pressure are not measured, but assumed constant.

Based on the sensitivity analysis and the other sources mentioned, some errors could be regarded as insignificant while others were severe. The different errors that can increase such that they will seriously affect the metering, without interrupting the operation of the meter, are: $U_{\text {liquid, }}$, the leakage terms $U_{\text {gasket }}, U_{\text {diaphragm }}, U_{\text {duct }}$ and the increased friction. Since these errors originate in the mechanical operation of the meter, it can be assumed that these errors affect the meter in such manner that they will be seen on the mechanical output. Therefore, a fingerprint of the meter will reflect the influence of the errors. The experimental work is focused on obtaining fingerprints from meters with simulated errors of these types and from meters used in the field.

\section{Experimental set-up}

To be able to simulate the influence of the errors caused by liquid in diaphragm $U_{\text {liquid }}$, the leakage terms $U_{\text {gasket, }}, U_{\text {diaphragm }}, U_{\text {duct }}$ and the increased friction on a meter, an experimental setup was constructed, consisting of a diaphragm meter and a pipe section (see Fig. 3). A brake could be attached to the meter to simulate increased friction. To measure the detailed operation of the meter, a measuring device, which was able to record, with high resolution, the rotation of the outgoing meter shaft, the proposed fingerprint, and the pressure difference over the meter, was assembled. The rotation was measured with an angular decoder that provides 100 pulses per revolution. In this manner, the pattern of the rotation is obtained. A series of pulses of equal value shows that the rotation is constant, but when a pulse is longer than the previous, the meter has either stopped or slowed down. The decoder is connected to a counter (Fluke PM 6681) which registers the duration and onset of each pulse (see Fig. 4). The pressure is measured with a Ruska 6222 pressure calibrator equipped with two pressure cells. The pressure is measured continuously and is read by a computer through GPIB. The computer controlling the instruments uses the Testpoint software

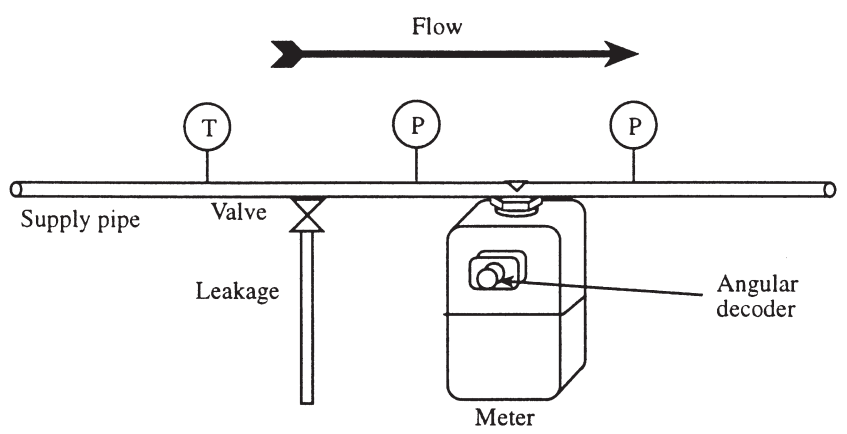

Fig. 3. Experimental set-up.

\begin{tabular}{|c|c|c|c|}
\hline Term & Value & Uncertainty & unit \\
\hline$R$ & 8.31434 & 0.00035 & $\mathrm{~J} / \mathrm{molK}$ \\
\hline$z$ & 1 & 0 & - \\
\hline$T$ & 288 & 6.4 & K \\
\hline$p_{\text {gas }}$ & 2000 & 50 & $\mathrm{~Pa}$ \\
\hline$p_{\text {atm }}$ & $101.325 \mathrm{e} 3$ & $1.0 \mathrm{e} 3$ & $\mathrm{~Pa}$ \\
\hline$r$ & 10 & 0 & - \\
\hline$G_{\text {stretch }}$ & 1 & & - \\
\hline$G_{\text {liquid }}$ & 1 & & - \\
\hline$G_{\text {stroke }}$ & 1 & & - \\
\hline$L_{\text {gasket }}$ & 1 & & - \\
\hline$L_{\text {diaphragm }}$ & 1 & & - \\
\hline$L_{\text {duct }}$ & 1 & & - \\
\hline
\end{tabular}

Table 1

Values for the different terms at normal conditions (for natural gas) 


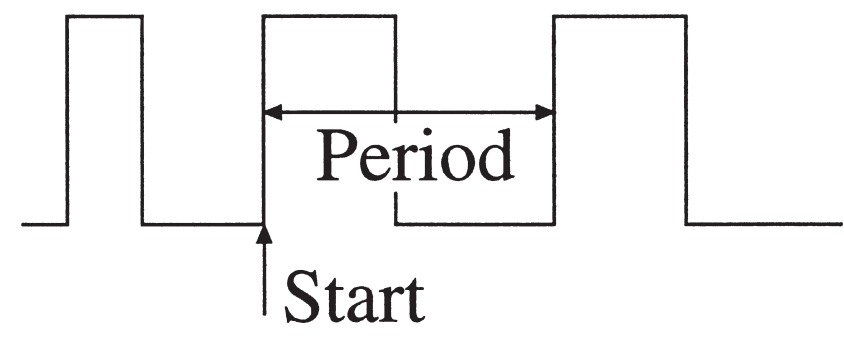

Fig. 4. Pulse from the decoder.

package to control the instrument through the GPIB interface. The analysis of the data is performed off-line using Matlab. The gas flow is provided by the calibration facility at LTH [21]. All tests are run with a constant gas flow of $1.0 \mathrm{~m}^{3} / \mathrm{h}$. To check the flow registered by the meter, the time for the test was recorded. Since all tests were made during 60 revolutions, the flow change, before and after an error was applied, could be calculated from the different test times.

In the previous chapter, errors that are likely to occur and seriously affect the metering or the connected appliance were determined. These include liquid in the meter, leakage and increased friction. It is these errors that will be simulated in the experiments.

Formation of liquid, $G_{\text {liquid }}$, in the measurement compartment is dependent on condensation of vapour in the gas, or water in the distribution grid. Although not related to the liquid in the measuring compartment, the effect on the meter is equal: the meter will go faster, due to lower volume in the measuring compartment. Two cases are of interest: 1) equal amounts in all compartments, and 2) different amounts in the compartments. In the first case, with equal amounts of liquid in each compartment, the effect will be an increasing frequency proportional to the volume reduction. It is, however, unlikely that the volume will be equal in all compartments. For the second case, with different amounts of liquid in each compartment, the effect will be twofold, the same as in the first case and an imbalance between the forward and rear compartments that is distinguishable in the fingerprint. The meter was disassembled and water was poured into one compartment. The meter was then assembled and tested.

The leakage corresponds to the different $L$ terms introduced in Eq. (5), which can all be tested in the same experiment, since all leakages affect the operation in the same way. The leakages that were found using the Load Index method described in [5] included: 1) fractures in the duct separating the inflow and outflow in the gas meter, 2) a misplaced gasket and 3) a punctured diaphragm. The leakage was simulated by using straight pipes of different lengths. By choosing the dimensions of the pipe, different leakages could be simulated. The pressure drop for a flow can be derived from Bernoulli's equation, and for straight pipes, its general expression is:
$\Delta p_{\text {fpipe }}=\lambda(R e) L / d \rho w^{2} / 2$

where $L$ is length, $d$ the diameter of the pipe, $\rho$ is the density, $w$ is the velocity, $\lambda(R e)$ is the friction coefficient. For other obstacles, it can be described as singular losses

$\Delta p_{\text {fleak }}=\xi(R e) \rho w^{2} / 2$

for a certain geometry on the obstacle. In many cases, the frictionloss coefficient, $\xi$, can be regarded as constant, i.e., independent of $R e$. If Eqs. (17) and (18) are compared, it can be seen that at the same Re, the dimensions of the pipe can be chosen to obtain the same pressure drop.

Regarding errors due to friction, it has been concluded that these primarily originate from the outgoing shaft, where the packing becomes dry or worn. Field experience from the local gas company confirms that increased friction is not uncommon for meters that ceased functioning. Sometimes the outgoing shaft is jammed by friction such that the shaft cannot even be turned with tools. To simulate how an increase in drag or friction in the outgoing shaft affects operation, a band brake was attached to the shaft, and an increasing braking force was applied. The band brake consisted of a rope around the shaft that connected the outgoing shaft with the decoder and a set of weights.

\section{Results}

The proposed fingerprint method has been tested on a number of meters, both new and used. As baseline data, a fingerprint from a new meter was obtained. To obtain the fingerprint from a defective meter, a used meter was tested with additional experimental equipment, allowing simulation of errors. Tests with meters coming from field use, which had errors, were also made. These confirmed that the change of the fingerprint from the simulated errors was comparable to the change in the fingerprint from meters with errors caused by usage.

The following two figures show the fingerprints from a new meter (Fig. 5) and a used meter (Fig. 6). Both the "fingerprint" and the differential pressure over the meter are given. The test lasted 60 revolutions or cycles, but for clarity, only the first 100 seconds are shown. The meter used in Fig. 5 is a new meter, of the same type and brand as the used meters that were tested later. The only difference is meter size, which explains the difference in pressure level and rotation frequency. The rotation of the new meter is smooth, with only one peak per cycle, and the pressure drop is almost constant.

Fig. 6 shows the fingerprint of a used meter $\left(10,500 \mathrm{~m}^{3}\right)$. Compared with Fig. 5, the basic pattern can 


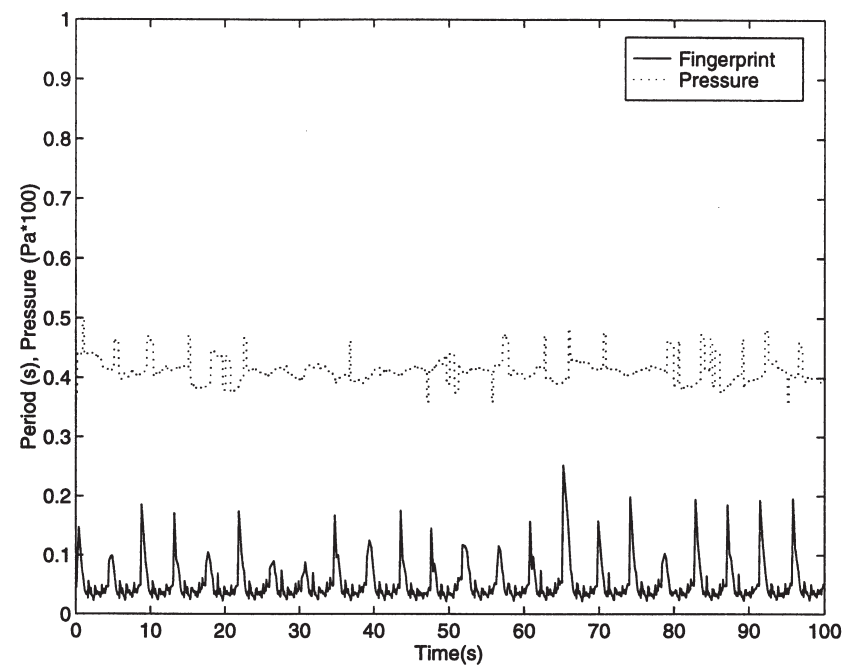

Fig. 5. Fingerprint and pressure of a new meter. The period data is the period between two pulses, i.e., a 100th of a revolution, and the units are seconds. The time scale on the abscissa is seconds.

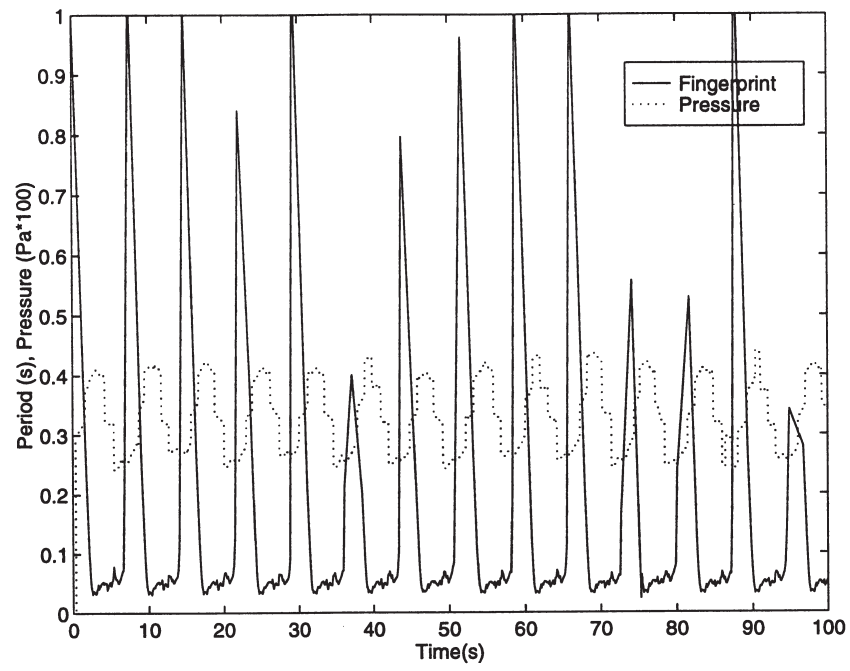

Fig. 6. Fingerprint and pressure of a used meter, 10,500 $\mathrm{m}^{3}$.

be recognised. However, the peaks are higher, there is a dip directly after the large peak and the pressures have changed to a more sinusoidal form. Translated to operation, this means that rotation is stopped at the end of one stroke, and the pressure build-up during this stop is used to increase the rotation when the torque overcomes the friction in the bearing (see Eq. (15)). The large peak is called friction peak, since the cause is mainly friction in the bearings. When a FFT analysis of the fingerprint is performed (Fig. 7), the result is one peak at the rotation frequency and overtones, as can be expected from a signal with one large peak.

In Fig. 8, the fingerprint of a meter with $50 \mathrm{ml}$ water in one measuring compartment is shown. It is the same meter as in the previous figure. The time for one test increased by $2 \%$ when the liquid was added. Since all

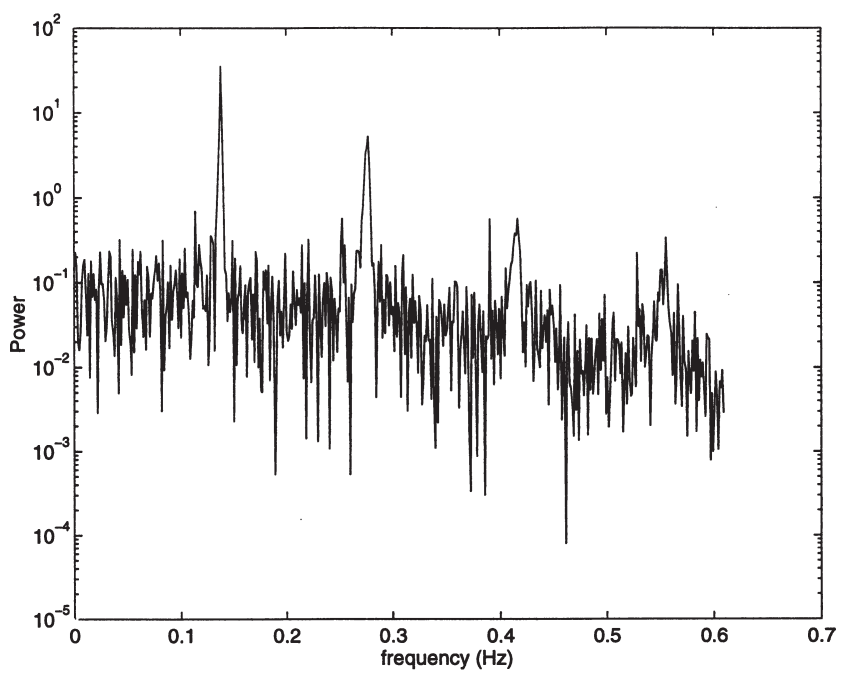

Fig. 7. FFT of the fingerprint in Fig. 6.

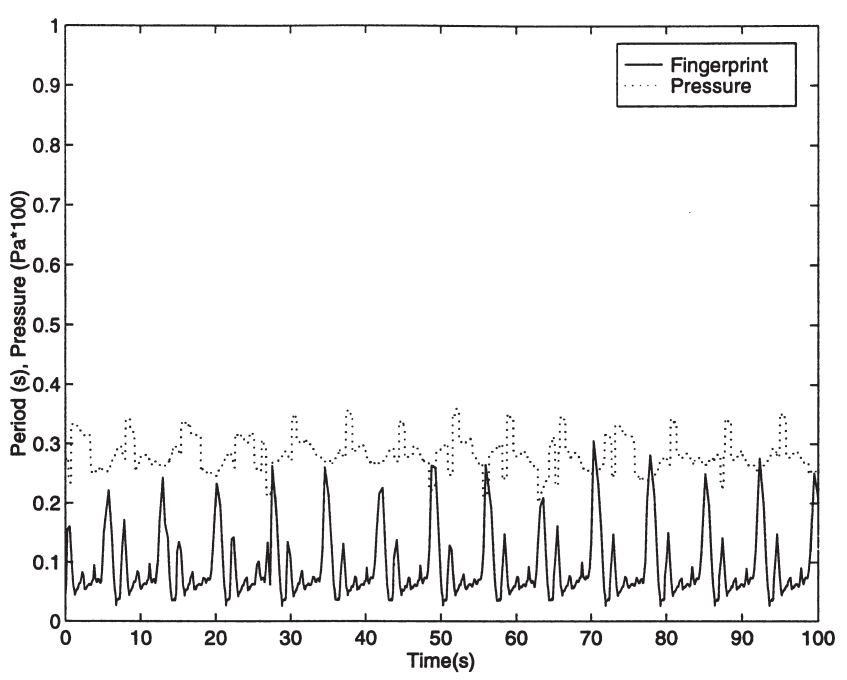

Fig. 8. Fingerprint and pressure from a meter with $50 \mathrm{ml}$ liquid in one measuring compartment.

tests are made at a constant flow rate of $1.0 \mathrm{~m}^{3} / \mathrm{h}$, this corresponds to a meter that measures $2 \%$ less than the actual flow.

The fingerprint changed from a single peak per cycle to four peaks, of which two are major. The four peaks represent the four phases in the measuring cycle. The second major peak is the friction peak, and the first major peak is due to the extra force needed to overcome the pressure from the liquid in the measuring compartment. When studying the FFT diagram in Fig. 9, the peaks are of approximately the same power, compared with Fig. 7, which shows the FFT of a normal meter where the power is descending from the rotation frequency. Several experiments, using three different meters and controlled leakages at six different levels, were performed in order to see how the fingerprint is affected. An example of a representative fingerprint is shown in Fig. 10. 


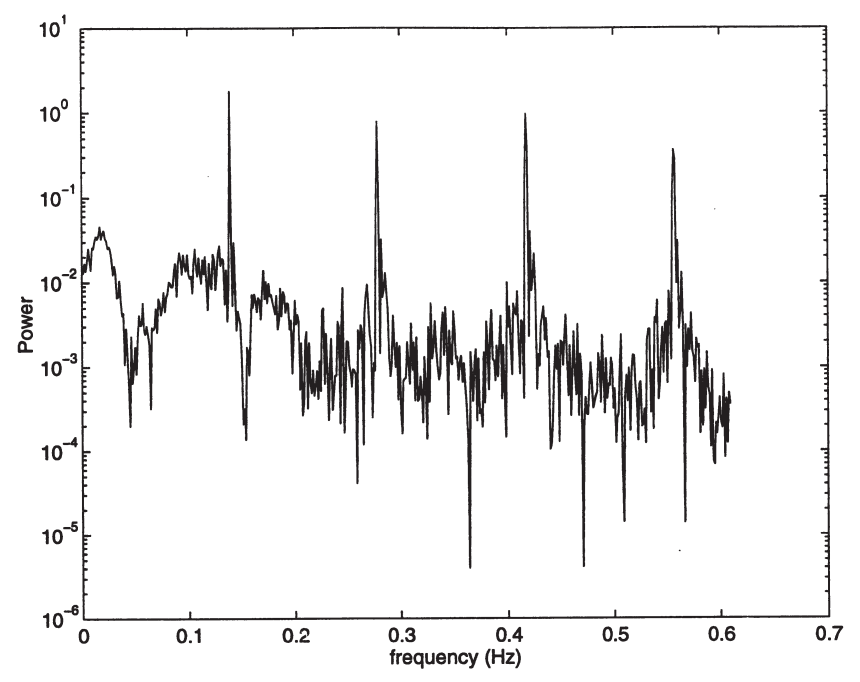

Fig. 9. FFT from the fingerprint in Fig. 8.

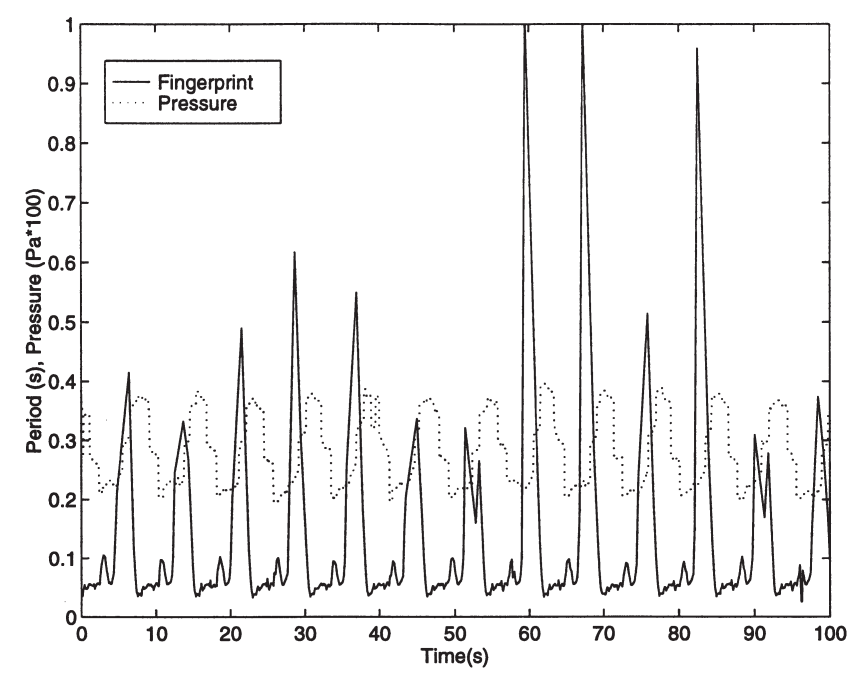

Fig. 10. The fingerprint and pressure of the meter of Fig. 9, with registered flow approx. $94 \%$ of the previous case.

Compared with the fingerprint from an undisturbed meter (Fig. 6), the same meter with a controlled leakage (Fig. 10) shows an extra peak at the pressure minimum, just before the friction peak. This is another stop in the operations at a stroke end. This can be explained by the lower available pressure head, due to a leakage that reduces the pressure that drives the mechanism. The gas will flow through the leakage until the pressure head across the leakage is equal to the pressure needed for meter operation, which will then restart. This peak at approx. $60 \%$ of the cycle is common for all tests with leakages.

To determine how increased friction affects the fingerprint, the brake described earlier was attached to the outgoing shaft. Varying braking torque was applied to the meter to test how it changed the fingerprint. The gas flow remained constant through the tests $\left(1.0 \mathrm{~m}^{3} / \mathrm{h}\right)$, so the measured volume is the same. According to Eq. (15), the gas pressure, $\Delta p_{\text {gas }}$, depends on the friction and necessary torque, and as can be seen when comparing the pressure in Fig. 6 with Fig. 11, increased friction leads to increased average pressure, but the pressure amplitude variation is not changed significantly.

The increased pressure difference will also lead to an increased volume when the diaphragm is stretched. The fingerprint was affected by friction in two ways. First, the maximum peak increased, and second, larger cycle to cycle variations were detected. As long as the inlet pressure is constant, the meter will continue to measure correctly, but the gas pressure necessary to operate the meter will increase until the meter stops. The increased pressure drop over the meter can also cause the connected appliance to stop functioning, due to low gas pressure.

After the method was tested using simulated errors, and shown to detect the described errors, it was used on a number of meters selected from a gas grid with the LoadIndex method. The meters had previously been tested at the LTH calibration rig and found to have errors ranging from -5 to $-20 \%$. The fingerprint from these meters showed the same pattern as the fingerprint from meters with simulated errors. Meters with fingerprints indicating leakage were found and disassembled. One had leakage in the duct, and others had holes in the diaphragms. Also, meters with increased friction were diagnosed correctly with the fingerprint method.

\section{Conclusion}

A fingerprint method to test diaphragm type gas flow meters in situ is proposed. Investigations have revealed the major sources of error to be: 1) liquid in measuring

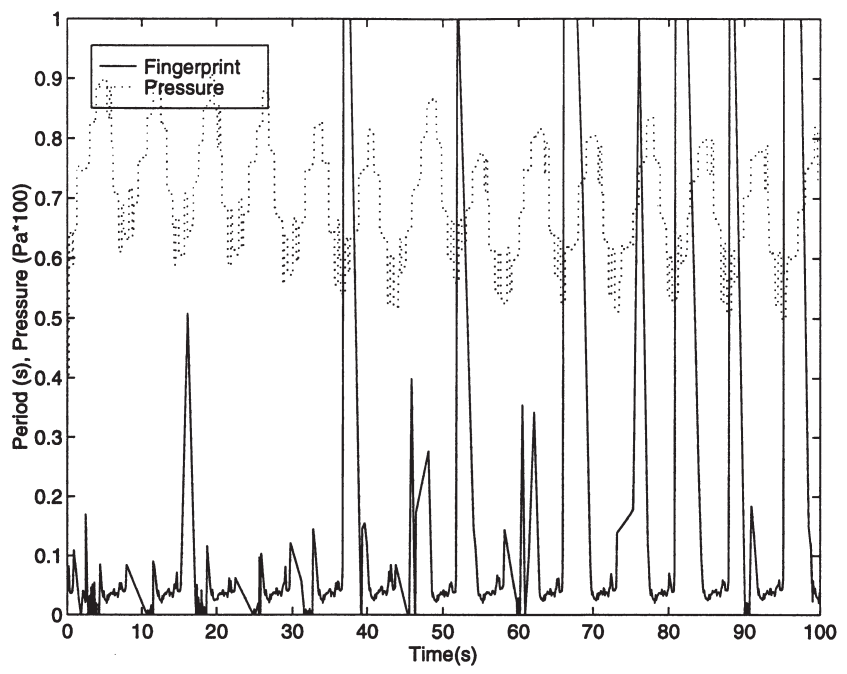

Fig. 11. Fingerprint and pressure from a meter with increased friction. 
compartment, 2) leakage in the meter and 3) increased friction in bearings. It has been shown that the fingerprint method has the ability to distinguish these sources of error.

Liquid in the measuring compartment can be detected as a fingerprint with four peaks per cycle. Leakage as small as $5 \%$ can clearly be seen in the fingerprint as a double peak per rotation, with the smaller at approx. $60 \%$ of the cycle. Increased friction can be seen as large variations from cycle to cycle.

The experiment has shown that the errors tested can be detected using the proposed method in the laboratory. Further tests on actual installations are needed to verify the usability of the fingerprint method and to determine the limits at which the meter should be exchanged. Thus far, the interpretation of the fingerprint has been made by visual interpretation of the fingerprint. This process can probably be automated in the future.

\section{Acknowledgements}

This work is sponsored by SGC (Swedish Gas Technology Centre). Thanks to Kurt Jönsson and Gert-Inge Glans, Lunds Energi AB and Nils Viding, Sydgas AB, for providing data and used meters for testing purposes and for fruitful discussions. Also, thanks to the Department of Heat and Power Engineering at Lund Institute of Technology, for providing facilities to conduct flow calibrations on flow meters.

\section{References}

[1] Meshkati S, Groot J. A study of the 1991 Unaccounted-For Gas Volume at the Southern California Gas Company, vols. I-VI, GRI-93/0115.s.

[2] Spitzer DW. Flow Measurement, ISA, ISBN 1-55617-334-2.3.
[3] Kuoppamäki R. On site calibration of district heating flow meters 23th Unichal Congress, Berlin 17-19 June, 1987.

[4] Sevel T. Anvendelsen af sporstoftteknik til in situ kontrol og kalibrering af flowmålere I spildevandssystemer, fjernvarmesystemer og gasflare systemer (in Danish), Den 16th nordiske konferanse Måleteknikk og Kalibrering. Helsingör, Denmark, 21-23 Nov 1994.

[5] Nilsson URC. A new method to find inaccurate gasflow meters using billing data, submitted to Flow Measurement and Instrumentation.

[6] Svensson B. In-Situ Test Methods in District Heating Systems. Licentiate Thesis, ISSN 0280-8242, Luleå, 1996.

[7] Lindahl EJ. Pulsation and its effects on flowmeters. Trans. ASME 1946;68:883-4.

[8] Oppenheim AK, Chilton EG. Pulsating flow measurement-A literature survey. Trans. ASME 1995;77:231-48.

[9] Mottram RC. The Measurement of pulsating flow using orifice plate meters. In: Dowedell ISA, editor. Flow, its measurement and control in science and industry, vol. 1. 1974:197-208.

[10] Mottram RC. An overview of pulsating flow measurement. Flow Measurement and Instrumentation 1992;3(3):114-7.

[11] McKee RJ. Pulsation effects on single and two rotor turbine meters. Flow Measurement and Instrumentation 1992;3(3):151-66.

[12] Atkinsson KN. A software tool to calculate the over registration error of a turbine meter in pulsating flow. Flow Measurement and Instrumentation 1992;3(3):167-72.

[13] Cheeswright R. Field tests of correction procedures for turbine flowmeters in pulsatile flows. Flow Measurement and Instrumentation 1996;7(1):7-17.

[14] Viljeer J, Ter Horst G. Monitoring Pulsation Errors in Turbine Meters. 19th World Gas Conference, Milan 20/23 June 1994, IGU/P-94.

[15] Gas Measurement Manual. Meter repair and selection. American Gas Association, Catalogue no. XQ0381.

[16] Coleman HW, Steele Jr WG. Experimentation and uncertainty analysis for engineers. ISBN 0-471-63517-0. John Wiley and Sons, 1989.

[17] Sydgas AB. Naturgas Handbok (in Swedish). Sydgas AB, 1991.

[18] Private communications with Lunds Energi AB.

[19] Väder, Vatten, (in Swedish) SMHI Swedish Meteorological and Hydrological Institute, ISSN 0281-9619.

[20] Mobers LPH. Über die Me $\beta$ genauigkeit von Haushaltzgaszählern in Holland, (in German), gwf Gas-Erdgas 129 1988;2:63-66.

[21] Delsing J. Low cost absolute calibration rig for gas flowmeters. 19th World Gas Conference, Milan 1994, IGU/PD3-94. 